\title{
Efficacy of fluralaner spot-on solution for the treatment of Ctenocephalides felis and Otodectes cynotis mixed infestation in naturally infested cats
}

\author{
Antonio Bosco ${ }^{1}$, Federico Leone ${ }^{2,3}$, Rosachiara Vascone ${ }^{1}$, Saverio Pennacchio ${ }^{1}$, Lavinia Ciuca', \\ Giuseppe Cringoli ${ }^{1}$ and Laura Rinaldi ${ }^{* *}$ (D)
}

\begin{abstract}
Background: Cats can be infested with several ectoparasite species, especially Ctenocephalides felis and Otodectes cynotis. The aim of this study was to evaluate the efficacy of a single topical application of fluralaner against C. felis and O. cynotis natural infestation in stray (study 1) and owned (study 2) cats in central and southern Italy.

Results: The number of live fleas found on each cat on Day 0 ranged from 1 to more than 30 (arithmetic mean live flea count $=11.9$ in study $1 ; 14.6$ in study 2) while no live fleas were found on days 7 and 84 post topical application of fluralaner. The number of live mites found on each cat on Day 0 ranged from 1 to 42 (arithmetic mean live mite count $=6.4$ in study $1 ; 8.9$ in study 2) while no live mites were found on days 7 and 84 post topical application of fluralaner.
\end{abstract}

Conclusions: Topical fluralaner completely eliminated fleas and ear mites from infested cats and was 100\% effective against both parasites up to 84 days after treatment.

Keywords: Ectoparasiticides, Fleas, Ear mites, Cats

\section{Background}

Cats can be infested with several ectoparasite species, particularly Ctenocephalides felis and Otodectes cynotis that are responsible for dermatitis and ear infestation respectively $[1,2]$. There are also some zoonotic pathogens such as Rickettsia felis and Bartonella felis, which can be transmitted by cat fleas [3]. In Europe the prevalence of flea infestations in cats ranges from $12 \%$ up to $70 \%[4,5]$ as in Spain, Germany and Austria [6]. In Italy the prevalence ranges from 3.7 to $31.6 \%$ [6].

On the other hand O. cynotis is responsible for feline otodectic mange, in $50-80 \%$ of cases of otitis externa [7] and is present in up to $66 \%$ of these in cats $[8,9]$. Ear mite infestation in cats may be complicated by

\footnotetext{
* Correspondence: Irinaldi@unina.it

${ }^{1}$ Department of Veterinary Medicine and Animal Production, University of Naples Federico II, Via Della Veterinaria 1, 80137 Naples, Italy

Full list of author information is available at the end of the article
}

secondary bacterial and fungal infection such as Staphylococcus spp. [10] and Malassezia spp. [9].

A multi-center study to determine the importance of O. cynotis revealed that it is the most prevalent ectoparasite of cats in Europe followed by C. felis [6]. In Italy, owned cats were found to be highly infested by these two ectoparasites, with values ranging from $31.6 \%$ for $O$. cynotis to $40.3 \%$ for C. felis [6].

Although there is high efficacy of antiparasitic molecules for the treatment and prevention of fleas [11] and mites $[7,12,13]$ in cats, re-infestations with both species of ectoparasites occur frequently.

Therefore effective year-long control measures should be adopted as suggested by the European Scientific Council of Companion Animal Parasites [14].

Fluralaner spot-on formulation is an isoxazoline ectoparasiticide effective against arthropoda including ticks and fleas on cats [15]. In the field study by Meadows et al. [2], fluralaner was $99 \%$ effective against

(c) The Author(s). 2019 Open Access This article is distributed under the terms of the Creative Commons Attribution 4.0 International License (http://creativecommons.org/licenses/by/4.0/), which permits unrestricted use, distribution, and reproduction in any medium, provided you give appropriate credit to the original author(s) and the source, provide a link to the Creative Commons license, and indicate if changes were made. The Creative Commons Public Domain Dedication waiver (http://creativecommons.org/publicdomain/zero/1.0/) applies to the data made available in this article, unless otherwise stated. 
Table 1 Ctenocephalides felis and Otodectes cynotis counts (arithmetic mean and range) before (Day 0) and after (Days 7 to 84) a single topical dose of fluralaner in naturally infested cats and percent of efficacy

\begin{tabular}{|c|c|c|c|c|}
\hline \multirow[t]{3}{*}{ Number of cats } & \multicolumn{2}{|c|}{ Ctenocephalides felis } & \multicolumn{2}{|c|}{ Otodectes cynotis } \\
\hline & Study 1 & Study 2 & Study 1 & Study 2 \\
\hline & $n=14$ & $n=25$ & $n=14$ & $n=25$ \\
\hline Mean parasite count & 11.9 & 14.6 & 6.4 & 8.9 \\
\hline Parasite count range (Day 0) & $1-30$ & $1-30$ & $1-21$ & $1-42$ \\
\hline Parasite count range (Days 7 to 84 ) & 0 & 0 & 0 & 0 \\
\hline Percent efficacy ${ }^{a}$ & 100 & 100 & 100 & 100 \\
\hline$P$ value & $<0.0001$ & $<0.0001$ & $<0.0001$ & $<0.0001$ \\
\hline
\end{tabular}

${ }^{\mathrm{a}}$ From Day 7 to Day 84

cat fleas from 4 to 12 weeks and $100 \%$ against O. cynotis during the 28-day observation period [15]. The aim of the present study was to evaluate the efficacy of a single treatment with a topical application of fluralaner against C. felis and O. cynotis natural infestations over 84 days.

\section{Results}

All cats were positive for the presence of fleas and ear mites prior to Day 0 of the study. No adverse reactions related to topical administration of fluralaner were observed in any cat during the study. The number of live fleas found on each cat on Day 0 ranged from 1 to more than 30 (arithmetic mean live flea counts $=11.9$ in study 1; 14.6 in study 2) while no live fleas were found up to day 84 (Table 1 ).

The number of live mites found on each cat on Day 0 ranged from 1 to 42 (arithmetic mean live mite counts = 6.4 in study $1 ; 8.9$ in study 2 ), while no live mites were found up to day 84 (Table 1 ).

At Day 0 of the study $1,1-5$ live fleas were recovered from the coat of 5 cats, $6-20$ live fleas were found on 2 subjects, 1 cat was infested with more than 30 fleas and on 6 cats abundant flea faeces were found. In the study $2,1-5$ live fleas were recovered from the coat of 7 cats, 6-20 fleas were found on 5 subjects, 3 cats were infested with more than 30 fleas and in 10 cats abundant amounts of flea faeces were present.

On Day 0 in study 1,10 cats had an otoscopic mite count of 1-5 mites, in the ears of 3 cats 6-20 mites were found and 1 cat was infested with more than 20 mites.

In the study 2, 11 cats had an otoscopic mite count of 1-5 mites, in 11 cats $6-20$ mites were found and 3 cats had a severe mite infestation (more than 20 mites).

In both studies from Day 7 no mites or fleas were found on any cats. No ear mites were seen in situ in any cats following ear flushing. At each post-treatment assessment, the arithmetic mean flea/mite count reductions from baseline were significant $(P<0.0001)$.

The percentage efficacy of a single topical treatment with the spot-on solution of fluralaner against fleas and
O. cynotis in naturally infested cats on Day 84 was calculated to be $100 \%$ based on arithmetic means.

The results of the pruritus/debris scoring are shown in Table 2. In both studies the severity of all clinical signs (pruritus on body and ears, head shaking, erythema, alopecia, excoriations, scratching and irritation at the ears) decreased over the course of the study starting as early as Day 7.

\section{Discussion}

A single topical dose of fluralaner completely eliminated fleas and ear mites in cats with mixed natural infestation by $C$. felis and $O$. cynotis, showing $100 \%$ efficacy against both ectoparasites at 84 days (12 weeks) after treatment.

Similarly to other ectoparasiticides of the isoxazolines class, fluralaner has a rapid action [16-19]; in our study, no fleas or mites were found 7 days after treatment. The complete control of both infestations lasted until the end of the study (day 84), the first time this has been shown for both species together making fluralaner a very valuable product for keeping cats free of infestations. Earlier studies had shown high activity of topical fluralaner against fleas for 12 weeks in naturally and experimentally infested cats $[19,20]$. Furthermore, the efficacy of fluralaner against otodectic mites was previously reported in experimentally infested cats $[1,15]$. In our present

Table 2 Percentage of cats showing clinical pruritus and debris scoring on Day $0(0=$ absent, $1=$ mild, $2=$ moderate, $3=$ sever $/$ abundant) ${ }^{a}$

\begin{tabular}{llllll}
\hline Score & \multicolumn{2}{l}{ Clinical pruritus scoring } & & \multicolumn{2}{c}{ Clinical debris scoring } \\
\cline { 2 - 3 } & Study 1 & Study 2 & & Study 1 & Study 2 \\
\hline 0 & 42.8 & 0.0 & & 0.0 & 0.0 \\
1 & 35.7 & 0.0 & & 0.0 & 8.0 \\
2 & 7.1 & 40.0 & & 7.14 & 28.0 \\
3 & 14.2 & 60.0 & & 92.8 & 64.0 \\
\hline
\end{tabular}

${ }^{a}$ In both studies the severity of all clinical signs (pruritus, head shaking, erythema) decreased over the course of the study starting as early as Day 7 up to Day 84 
Table 3 Design of the study

\begin{tabular}{|c|c|}
\hline Study day & Event \\
\hline Day -60 & $\begin{array}{l}\text { - Inspection of the cattery } \\
\text { - Clinical examination of the subjects }\end{array}$ \\
\hline Day 0 & - Application of fluralaner \\
\hline Days $7,14,28,56,84$ & $\begin{array}{l}\text { - Coat examination } \\
\text { - Otoscopic examination } \\
\text { - Cytological examination of the ear material } \\
\text { - Clinical scoring }\end{array}$ \\
\hline Days $28,56,84$ & - Ear flushing \\
\hline
\end{tabular}

a Clinical scoring system. Pruritus $(0=$ absent, $1=$ mild, $2=$ moderate, $3=$ sever $)$; debris scoring $(0=$ absent; $1=$ mild, $2=$ moderate, $3=$ abundant $)$

study, improvements in pruritus and otic clinical signs were observed after fluralaner treatment, and persisted up to Day 84.

In a similar study, the efficacy of afoxolaner in the treatment of natural infestations by $O$. cynotis in cats was shown but only for up to 35 days after the treatment [18].

In the present study there were no control groups, but the treated stray cats continued to live in close contact with other untreated infested cats during the trial so would have been exposed to flea (C. felis) and mite (O. cynotis) challenge.

\section{Conclusions}

A single topical administration of fluralaner solution to cats is highly effective for controlling mixed flea and otodectic mite infestations, showing effective control for 3 months post-treatment.

\section{Methods}

The study was conducted from February to July 2017 on stray (study 1) and owned (study 2) cats from two different geographical regions, Campania (southern Italy) and
Marche (central Italy). Stray cats were recruited from a cattery located in the Campania region while the owned cats were recruited from two private clinics located in the Campania and Marche regions. This research was conducted with the approval of the Animal Care Committee of the Department of Veterinary Medicine and Animal Productions, University of Naples Federico II (protocol number 0041919/2017). All procedures were conducted in compliance with the ethical principles of good practice in animal experimentation.

\section{Animals}

All animals were managed in the same way with regard to welfare and owner informed consent was obtained to use the cats. Enrollment criteria included cats of at least 11 weeks of age weighing at least $1.2 \mathrm{~kg}$. None of the animals had been treated with acaricide or insecticide products for at least 12 weeks prior to this research.

\section{Study design and treatment}

The study population consisted of 39 European breeds of cats ( 21 females and 18 males) divided in two groups (14 stray cats in study 1 and 25 owned cats in study 2), with weights ranging from $1.8 \mathrm{~kg}$ to $8.5 \mathrm{~kg}$ and between 1 and 8 years of age. Sixty days before treatment all cats were examined for clinical signs related to the presence of fleas and mites and suitability for the trial. All cats received a single dose $(40 \mathrm{mg} / \mathrm{kg})$ of fluralaner spot-on solution (Bravecto ${ }^{\oplus}$ spot-on, MSD Animal Health) on day 0 . All treatments were applied by vets directly on the skin at the base of the skull, by squeezing the contents onto one or more spots according to the manufacturer's instructions. Cats were checked for $24 \mathrm{~h}$ after dosing with follow-up performed at 7, 14, 28, 56 and 84 days to evaluate the effectiveness of fluralaner (Table 3 ).

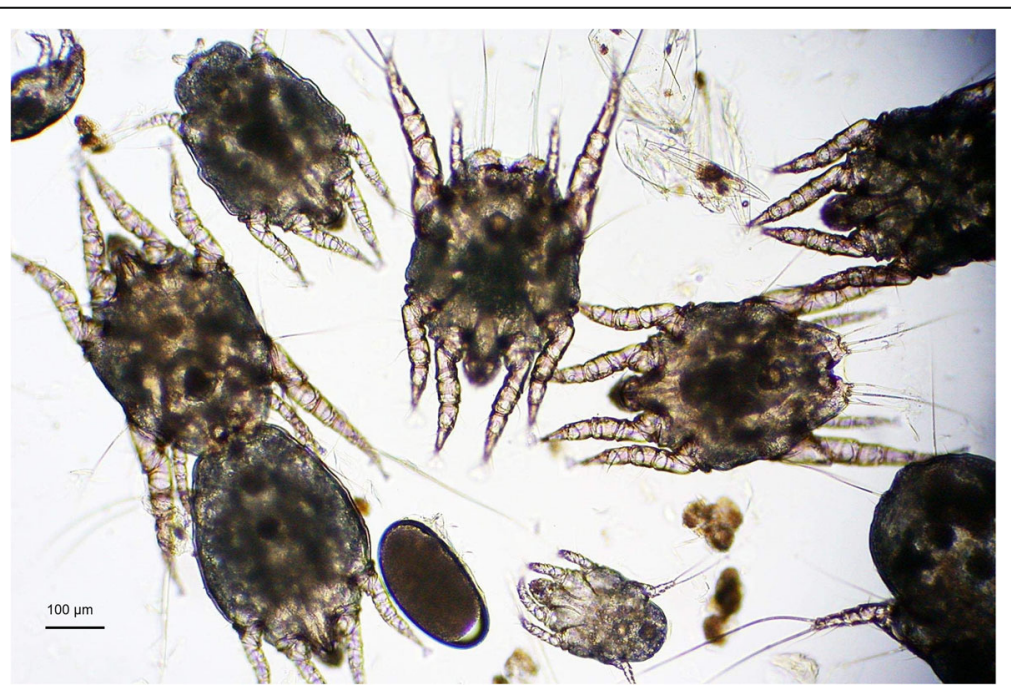

Fig. 1 Microscopic examination of the auricular secretion of a cat infested by different stages of O. cynotis 


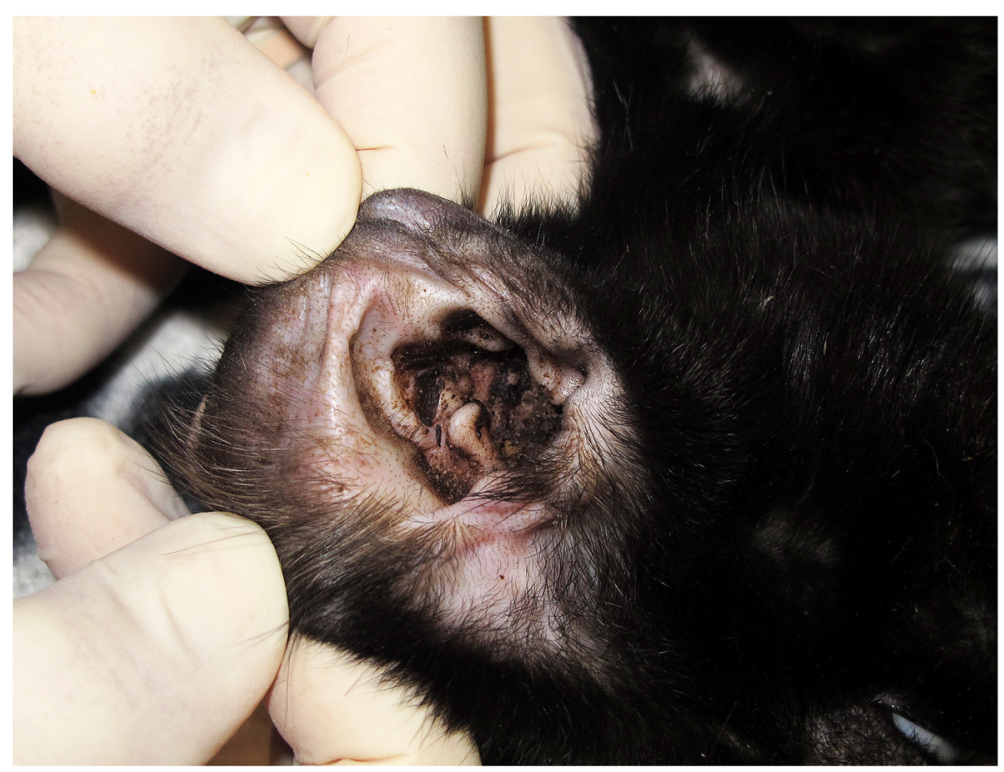

Fig. 2 Auricular secretion with a characteristic "coffee ground" appearance in a cat affected by otoacariosis

\section{Assessment of flea infestation}

Prior to enrollment in the study, cats were proved to have existing flea infestations by a coat examination with a fine-toothed brush [21] and finding flea faeces and clinical examination for signs of infestation.

\section{Assessment of $O$. cynotis infestation}

Prior to enrollment, O. cynotis infestation was confirmed by direct or otoscopic examination of the external ear canal of both ears. On 28, 56 and 84 days post-treatment cats were sedated with dexmedetomidine hydrochloride

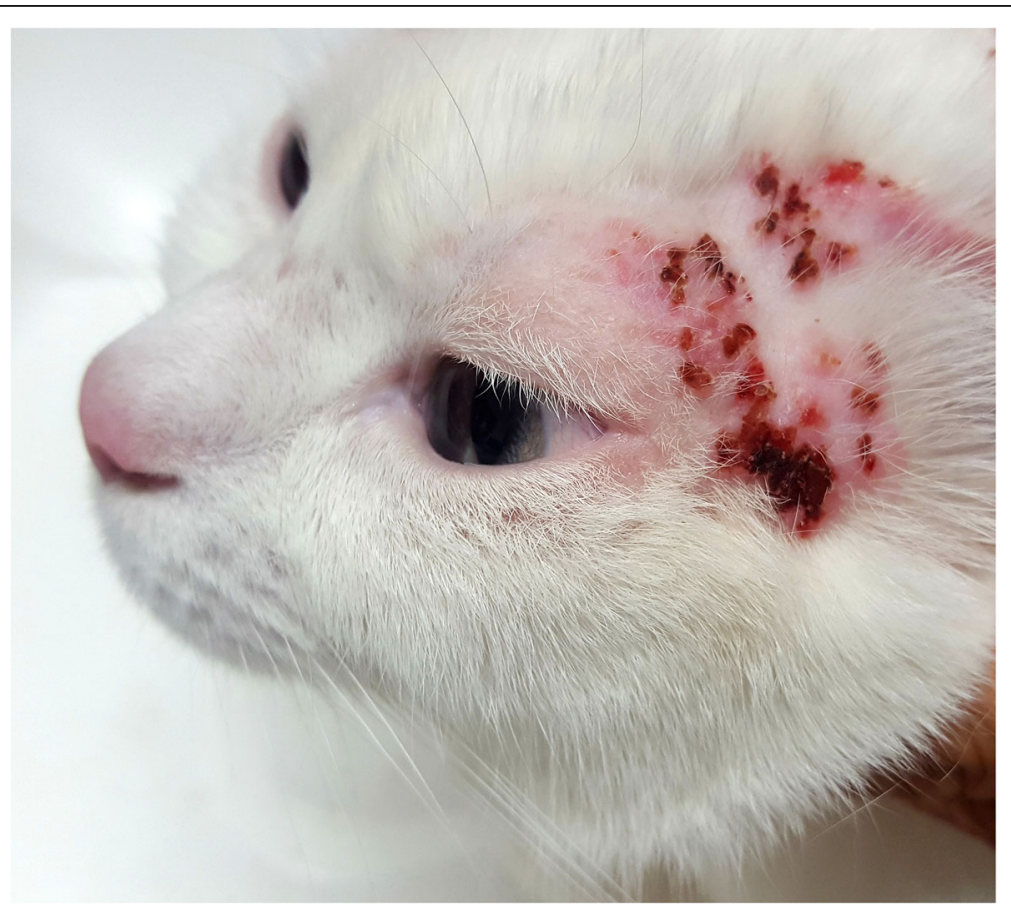

Fig. 3 Self-traumatism injuries due to Otodectes cynotis in an infested cat 
(40 $\mu \mathrm{g} / \mathrm{kg} \mathrm{IM})$, the ear ducts were filled with a solution of $0.9 \%$ sodium chloride ( 3 to $5 \mathrm{ml}$ per ear canal).

and the ears were massaged externally to displace the content. The collected material was placed on slides and observed microscopically for immature and adult live mites (Fig. 1).

\section{Assessment of clinical signs}

The clinical signs of infested cats before the treatment varied in severity from one cat to another and included pruritus, alopecia, papules, scales, crusts, excoriations, head shaking, erythema, ulceration and debris in the ear canal (Figs. 2 and 3).

Furthermore, during the clinical visit a score (Table 3) for each cat was awarded for pruritus $(0=a b-$ sent, $1=$ mild, $2=$ moderate, $3=$ severe) as described by Meadows et al. [2] and for ear debris $(0=$ absent; $1=$ mild, $2=$ moderate, $3=$ abundant) [22] .

\section{Efficacy evaluation}

In both studies, the primary efficacy criterion was the number of live fleas/mites (in all stages) collected from the two groups (stray and owned cats) from 0 to 84 days post treatment. The average percent reduction in the flea/mite count was calculated using the following formula (adapted from Marchiondo et al. [23]):

$$
\% \text { Efficacy }=\frac{\text { Mean F/M Day 0-F/M Days } 7,14,28,56,84}{\text { Mean F/M Day } 0}
$$$$
\times 100
$$

where:

$\mathrm{F}=$ mean live flea count;

$\mathrm{M}=$ mean live mite count.

After the study, all the cats involved in the two trials (study 1 and study 2) returned to their normal living conditions (cattery or home) and received regular veterinary care.

\section{Abbreviations}

F: Mean live flea count; M: Mean live mite count

\section{Acknowledgements}

We acknowledge Prof. Gerald Coles for helping in the English revision.

\section{Funding}

No funding was obtained for this study.

\section{Availability of data and materials}

The datasets used and/or analysed during the current study are available from the corresponding author on reasonable request.

\section{Authors' contributions}

$A B, F L, R V, S P$ and $L C$ participated in the design of the study, performed treatments, monitored the field studies, conducted laboratory analyses and drafted the paper. CG and LR contributed to the design and supervision of the studies and helped drafting the manuscript. All the authors read and approved the final manuscript.

\section{Ethics approval}

The study protocol was approved by the Animal Care Committee at the Department of Veterinary Medicine and Animal Productions, University of Naples Federico II (protocol number 0041919/2017).

\section{Consent for publication}

Not applicable.

\section{Competing interests}

The authors declare that they have no competing interests.

\section{Publisher's Note}

Springer Nature remains neutral with regard to jurisdictional claims in published maps and institutional affiliations.

\section{Author details}

1Department of Veterinary Medicine and Animal Production, University of Naples Federico II, Via Della Veterinaria 1, 80137 Naples, Italy. ${ }^{2}$ Clinica Veterinaria Adriatica, Senigallia, Ancona, Italy. ${ }^{3}$ Laboratorio di Analisi Veterinarie La Vallonea, Passirana di Rho, Milano, Italy.

Received: 15 June 2018 Accepted: 7 January 2019

Published online: 16 January 2019

\section{References}

1. Taenzler J, de Vos C, Roepke RKA, Heckeroth AR. Efficacy of fluralaner plus moxidectin (Bravecto ${ }^{\oplus}$ plus spot-on solution for cats) against Otodectes cynotis infestations in cats. Parasit Vectors. 2018;11(1):595.

2. Meadows C, Guerino F, Sun F. A randomized, blinded, controlled USA field study to assess the use of fluralaner topical solution in controlling feline flea infestations. Parasit Vectors. 2017:10:37.

3. Silaghi C, Knaus M, Rapti D, Shukullari E, Pfister K, Rehbein S. Rickettsia felis and Bartonella spp. in fleas from cats in Albania. Vector Borne Zoonotic Dis. 2012;12:76-7.

4. Bond R, Riddle A, Mottram L, Beugnet F, Stevenson R. Survey of flea infestation in dogs and cats in the United Kingdom during 2005. Vet Rec. 2007:160:503-6.

5. Farkas R, Gyurkovszky M, Solymosi N, Beugnet F. Prevalence of flea infestation in dogs and cats in Hungary combined with a survey of owner awareness. Med Vet Entomol. 2009:23:187-94.

6. Beugnet F, Bourdeau P, Chalvet-Monfray K, Cozma V, Farkas R, Guillot J, et al. Parasites of domestic owned cats in Europe: co-infestations and risk factors. Parasit Vectors. 2014;7:291.

7. Yang C, Huang HP. Evidence-based veterinary dermatology: a review of published studies of treatments for Otodectes cynotis (ear mite) infestation in cats. Vet Dermatol. 2016:27:221-56.

8. Nardoni S, Ebani W, Fratini F, Mannella R, Pinferi G, Mancianti F, et al. Malassezia, mites and bacteria in the external ear canal of dogs and cats with otitis externa. Slov Vet Res. 2014;51:113-8.

9. Perego R, Proverbio D, Bagnagatti De Giorgi G, Della Pepa A, Spada E. Prevalence of otitis externa in stray cats in northern Italy. J Feline Med Surg. 2014;16:483-90

10. Roy J, Bédard C, Moreau M. Treatment of feline otitis externa due to Otodectes cynotis and complicated by secondary bacterial and fungal infections with Oridermyl auricular ointment. Can Vet J. 2011;52:277-82.

11. Rust MK. Advances in the control of Ctenocephalides felis (cat flea) on cats and dogs. Trends Parasitol. 2005:21:232-6.

12. Curtis CF. Current trends in the treatment of Sarcoptes, Cheyletiella and Otodectes mite infestations in dogs and cats. Vet Dermatol. 2004:15:108-14.

13. Beugnet F, Bouhsira E, Halos L, Franc M. Preventive efficacy of a topical combination of fipronil--(S)-methoprene--eprinomectin--praziquantel against ear mite (Otodectes cynotis) infestation of cats through a natural infestation model. Parasite. 2014;21:40

14. European Scientific Counsel Companion Animal Parasites. 2018. https:// www.esccap.org. Acessesed 15 May 2018

15. Taenzler J, De Vos C, Roepke RK, Frénais R, Heckeroth AR. Efficacy of fluralaner against Otodectes cynotis infestations in dogs and cats. Parasit Vectors. 2016:10:30.

16. Review- SPAT. Isoxazolines. J Exotic Pet Med. 2018;27:118-22. 
17. Letendre L, Huang R, Kvaternick V, Harriman J, Drag M, Soll M. The intravenous and oral pharmacokinetics of afoxolaner used as a monthly chewable anti-parasitic for dogs. Vet Parasitol. 2014;201:190-7.

18. Machado MA, Camposb DR, Lôres Lopesc NL, Bastosd IPB, Botelhoc CB, Correiae TR, et al. Efficacy of afoxolaner in the treatment of otodectic mange in naturally infested cats. Vet Parasitol. 2018;256:29-31.

19. Dryden MW, Canfield MS, Bocon C, Phan L, Niedfeldt E, Kinnon A, et al. Inhome assessment of either topical fluralaner or topical selamectin for flea control in naturally infested cats in west Central Florida, USA. Parasit Vectors. 2018;11:422.

20. Ranjan S, Young D, Sun F. A single topical fluralaner application to cats and to dogs controls fleas for 12 weeks in a simulated home environment. Parasit Vectors. 2018;11:385.

21. Franc M, Beugnet F. Flea infestations. In: Parasitoses and vector borne diseases of cats. Scientific Editors Beugnet F. and Halos L. Merial: Lyon; 201. p. 151-160.

22. Six RH, Clemence RG, Thomas CA, Behan S, Boy MG, Watson P, et al. Efficacy and safety of selamectin against Sarcoptes scabiei on dogs and Otodectes cynotis on dogs and cats presented as veterinary patients. Vet Parasitol. 2000;91:291-309.

23. Marchiondo AA, Holdsworth PA, Fourie LJ, Rugg D, Hellmann K, Snyder DE, et al. Guidelines for evaluating the efficacy of parasiticides for the treatment prevention and control of flea and tick infestations on dogs and cats. 2nd ed. world association for the advancement of veterinary parasitology. Vet Parasitol. 2013;194(1):84-97.

Ready to submit your research? Choose BMC and benefit from:

- fast, convenient online submission

- thorough peer review by experienced researchers in your field

- rapid publication on acceptance

- support for research data, including large and complex data types

- gold Open Access which fosters wider collaboration and increased citations

- maximum visibility for your research: over $100 \mathrm{M}$ website views per year

At $\mathrm{BMC}$, research is always in progress.

Learn more biomedcentral.com/submissions 